\title{
A RECONTEXTUALIZAÇÃO DO CURRÍCULO DE LÍNGUA PORTUGUESA NA SALA DE AULA DE UMA ESCOLA QUILOMBOLA
}

\author{
Elenilson Evangelista Silva* \\ Benedito Eugenio
}

RESUMO: Este artigo apresenta os resultados de uma pesquisa etnográfica, por meio de observações, entrevistas e análise documental, cujo objetivo é analisar o processo de recontextualização na disciplina de Língua Portuguesa em uma turma multisseriada de $1^{\circ}$ e $2^{\circ}$ anos do ensino fundamental de uma escola quilombola situada na comunidade de Baixão, localizada no município de Vitória da Conquista. Para a análise dos dados, utilizamos a teoria sociológica de Bernstein (1996), nos atendo particularmente sobre os campos recontextualizadores oficial e pedagógico. A prática curricular da professora apresenta indícios que permitem considera-la como pedagogia visível.

PALAVRAS-CHAVES: Recontextualização. Ensino de Língua Portuguesa. Educação Escolar Quilombola. Currículo.

\section{Introdução}

Neste artigo, apresentamos parte dos resultados de uma pesquisa sobre a recontextualização do currículo na disciplina de Língua Portuguesa em uma escola quilombola localizada na comunidade do Baixão, em Vitória da Conquista-Ba.

Muitos pesquisadores têm realizado estudos sobre a recontextualização do conhecimento em diferentes disciplinas e/ou conteúdos/propostas curriculares, a exemplo de Eugenio (2009, 2017), Stefenon (2017), Pereira (2017), Bezerra (2018), Alferes e Mainardes (2018), Galian (2009), Souza (2015).

A recontextualização é interpretada por Mainardes e Stremel (2010, p. 13) como

Um princípio que tira um discurso de sua prática e contexto de origem e reloca aquele discurso de acordo com seu próprio princípio de focalização e reordenamentos seletivos. Nesse processo, o discurso real (original) passa por uma transformação, criando um discurso imaginário ou virtual (discurso recontextualizado)

\footnotetext{
${ }^{*}$ Mestrando em Ensino pela Universidade Estadual do Sudoeste da Bahia (Uesb).

${ }^{* *}$ Doutor em Educação pela Universidade Estadual de Campinas (Unicamp). Atualmente é professor Titular da Universidade Estadual do Sudoeste da Bahia (Uesb).
} 
Conforme Bernstein (1996, p. 254), o dispositivo pedagógico "fornece a gramática intrínseca do discurso pedagógico, por meio de três regras, que estão hierarquicamente relacionadas, de modo que uma regula a outra". Assim sendo, "as regras distributivas regulam as regras recontextualizadoras, as quais, por sua vez, regulam as regras de avaliação".

É valendo dessa abordagem que caracterizamos a prática de uma professora na disciplina de Língua Portuguesa. Para isso, utilizamos um protocolo estruturado com 7 (sete) categorias presentes na teoria de Bernstein (1996), quais sejam: a) fronteiras de espaços entre alunos e professores; b) relações de comunicação; c) critérios de avaliação; d) ritmos de aprendizagem; e) relações intradisciplinares; f) nível de exigência conceitual; e g) nível de proficiência investigativa.

O artigo está assim organizado: inicialmente situamos a metodologia e o local da pesquisa; na sequência pontuamos algumas considerações sobre o currículo e sobre o campo recontextualizador oficial para o ensino de Língua Portuguesa nos anos iniciais; depois analisamos a recontextualização no campo recontextualizador pedagógico.

\section{Situando a metodologia e o local da investigação}

Construímos os dados deste artigo por meio de uma pesquisa etnográfica realizada em uma turma multisseriada de $1^{\circ}$ e $2^{\circ}$ anos dos anos iniciais do ensino fundamental em uma escola quilombola na comunidade do Baixão, no município de Vitória da ConquistaBA. Este tipo de pesquisa "visa compreender, na sua cotidianidade, os processos do dia-adia em suas diversas modalidades. Trata-se de um mergulho no micro social, olhando com uma lente de aumento. Aplica métodos e técnicas compatíveis com a abordagem qualitativa" (SEVERINO, 2007, p. 119).

De acordo com Angrosino (2009, p. 16), etnografia significa literalmente a descrição de um povo, sendo muito útil para estudar questões ou comportamentos sociais que ainda não foram compreendidos.

Permanecemos na escola por 45 dias fazendo observações na sala de aula, o que nos permitiu fazer uma descrição densa sobre a prática da professora na medida em que 
demonstramos à luz da teoria sociológica de Bernstein como se efetivam suas práticas curriculares

Entendendo a etnografia como uma descrição densa e como um processo de construção, Gertz (1989, p. 15) aponta que

Praticar a etnografia é estabelecer relações, selecionar informantes, transcrever textos, levantar genealogias, mapear campos, manter um diário, e assim por diante. Mas não são essas coisas, as técnicas e os processos determinados, que definem o empreendimento. O que define é o tipo de esforço intelectual que ele representa: um risco elaborado para uma "descrição densa" [...]. Fazer etnografia é como tentar ler (no sentido de "construir uma leitura de") um manuscrito estranho, desbotado, cheio de elipses, incoerências, emendas suspeitas e comentários tendenciosos, escrito com os sinais convencionais do som, mas com exemplos transitórios de comportamento modelado.

Para Eugenio (2018, p. 7), os estudos etnográficos preocupam-se em compreender/apreender a realidade dos sujeitos estudados, o que requer:

Permanência prolongada do investigador no contexto estudado, interesse por todos os traços e pormenores que fazem o cotidiano, interesse dirigido para comportamentos e atitudes dos sujeitos sociais e as interpretações que fazem desse comportamento; esforço em produzir um relato que recrie de forma viva os fenômenos estudados; esforço em estruturar progressivamente o conhecimento obtido, de modo que o processo hermenêutico resulte da construção dialógica e continuamente compreensiva das interpretações e ações dos indivíduos no contexto estudado.

Oliveira, Boin e Búrigio (2018) trazem uma contribuição importante para o emprego da pesquisa etnográfica em educação problematizando seus desafios, limites e possibilidades. Dentre alguns enfoques, destacam-se os estudos de comunidades, o advento das políticas educacionais voltadas para a diversidade cultural, a ampliação do acesso à escolarização das populações indígenas e quilombolas, bem como o direito à educação diferenciada desses grupos e, mais recentemente, as ações afirmativas. 
Para Geertz (2008, p. 7), o etnógrafo tem que apreender a cultura ou a realidade de forma inteligível. Assim, o pesquisador observa, registra e analisa. Realizamos nossa etnografia nessa perspectiva, buscando compreender por meio de análises do contexto micro como o currículo numa escola quilombola é recontextualizado.

Para a construção dos dados, utilizamos a observação participante, entrevista e análise de documentos, pois como afirma Angrosino (2009) uma boa etnografia geralmente resulta dessa triangulação. Essas técnicas e procedimentos nos permitiram visualizar o processo de recontextualização das práticas curriculares nas aulas da disciplina de Língua Portuguesa em uma turma multisseriada do $1^{\circ}$ e $2^{\circ}$ ano do ensino fundamental em uma escola quilombola no município de Vitória da Conquista-Ba. A pesquisa foi aprovada pelo Comitê de Ética em Pesquisa da Universidade Estadual do Sudoeste da Bahia, sob o número 3.425.407.

A comunidade quilombola do Baixão localiza-se no município de Vitória da Conquista-Ba, situada no sentido oeste da cidade, a aproximadamente $13 \mathrm{Km}$ do centro, fazendo fronteira com o distrito do Pradoso. A comunidade é de fácil acesso, tendo ônibus circulares e vans que vão pela estrada principal e logo após o aterro sanitário e bem antes do posto da Polícia Rodoviária Federal há uma entrada pelo lado direito que adentra a localidade pelas estradas vicinais.

A Escola Quilombola Jorge Amado, doravante EQJA, funciona nos turnos matutino e vespertino, atendendo quatro turmas multisseriadas, em um quantitativo de 89 alunos nos segmentos de Educação infantil e Ensino Fundamental nos anos iniciais. Está assim organizada: de manhã há duas turmas - uma da Pré-escola com 21 alunos e outra do $3^{\circ}$ ao $4^{\circ}$ ano com 23 alunos; já à tarde, há uma turma de $1^{\circ}$ e $2^{\circ}$ ano com 22 crianças e outra do $3^{\circ}$ e $4^{\circ}$, com 23 discentes.

A EQJA é considerada de pequeno porte, foi construída no início dos anos de 1980, sendo o terreno doado por José Machado dos Santos, filho do patriarca João Machado dos Santos. Segundo Lima (2018), há uma reivindicação da comunidade para mudar o nome da escola para o nome do doador do terreno. Nas entrevistas com a professora Ivani e com 
uma moradora da comunidade, elas nos demonstraram insatisfação com o nome de uma pessoa que não representa a história da comunidade.

\section{Algumas considerações sobre o currículo na teoria de Bernstein}

Nosso trabalho apoia-se nas teorias críticas, mais precisamente na teoria do discurso pedagógico de Basil Bernstein (1996) sociólogo da Nova Sociologia da Educação (NSE).

De acordo com a teorização de Bernstein, é possível visualizar dois tipos de currículos, o de integração e o de coleção. O currículo de integração é característico dentro da pedagogia invisível e o de coleção da pedagogia visível definindo assim há dois tipos de prática pedagógica que realiza explicitamente ou implicitamente.

Segundo Bernstein (1996, p. 103), na prática pedagógica visível (PV) as regras de ordem regulativa e discursiva são critérios explícitos de hierarquia/sequência/compassamento. Esse tipo de transmissão sempre colocará a ênfase no desempenho da criança, produzindo diferenças entre elas. Contrariamente, na pedagogia invisível (PI) as regras de ordem regulativa e discursiva são implícitas, conhecidas apenas pelo transmissor.

De acordo com Bernstein (1996, p. 105), "a ênfase entre as pedagogias visíveis e invisíveis afetarão claramente tanto a seleção quanto organização daquilo que deve ser adquirido". Esse conhecimento transmitido e adquirido visível ou invisivelmente se dá por meio da recontextualização, conceito fulcral na teoria bernsteiniana, compreendido como discurso pedagógico, ou seja, o conhecimento curricular reinterpretado.

Conforme Bernstein (1996, p. 259),

O discurso pedagógico é um princípio para apropriar outros discursos e coloca-los numa relação mútua especial, com vistas à sua transmissão e aquisição seletivas. O discurso pedagógico é, pois, um processo que tira (desloca) um discurso de sua prática e contextos substantivos e recola aquele discurso de com seu próprio princípio de focalização e reordenamentos seletivos. Nesse processo de deslocação e relocação do discurso original, a base social de sua prática (incluindo suas relações de poder) é eliminada. Nesse processo de deslocação e relocação, o discurso original passa por uma transformação: de uma prática real para uma prática virtual ou imaginária. $\mathrm{O}$ discurso pedagógico cria sujeitos imaginários. É preciso refinar esse conceito sobre o princípio que constitui o discurso pedagógico. 
Trata se de um princípio recontextualizador que, seletivamente, apropria, refocaliza e relaciona outros discursos, para constituir sua própria ordem e seus próprios ordenamentos.

Nesse processo, Bernstein destaca dois campos recontextualizadores: o Campo Recontextualizador Oficial (CRO) e o Campo Recontextualizador Pedagógico (CRP). O autor descreve que o campo recontextualizador oficial (CRO) é "regulado diretamente pelo Estado, politicamente através da administração pública" e nos campos recontextualizadores pedagógicos (CRP) “estão preocupados com os princípios e práticas que regulam a circulação de teorias e textos: do contexto de sua produção ou existência para os contextos de sua reprodução" (BERNSTEIN, 1996, p. 277).

$\mathrm{Na}$ discussão deste artigo, fazem parte do CRO a Base Nacional Curricular Comum - BNCC, o Plano Nacional de Alfabetização na Idade Certa - PNAIC, o Plano Municipal de Educação, o Plano anual para a disciplina de Língua Portuguesa. Ao passo que esses documentos são recontextualizados, fazem parte do CRP a prática pedagógica da professora, como veremos nos próximos tópicos.

\section{O campo recontextualizador oficial para o ensino de Língua Portuguesa nos anos} iniciais

De acordo com Bernstein (1996, p. 272), “o campo recontextualizador oficial são regras oficiais que regulam a produção, distribuição, reprodução, inter-relação e mudanças dos textos pedagógicos legítimos" (discursos). Assim, esse campo é criado e dominado pelo Estado.

No discurso pedagógico oficial para o ensino de Língua Portuguesa analisamos o que diz a Base Nacional Comum Curricular- BNCC, o Plano Nacional de Implementação de Relações Étnico-raciais, as Diretrizes Curriculares Estaduais para a Educação Escolar Quilombola, e o Plano Municipal de Educação bem como o plano anual. Estes documentos se encontram em nível nacional, e municipal, entendidos respectivamente também como nível macro e nível meso. 
No âmbito nacional, no nível macro em atendimento à Portaria $n^{\circ} 867$, de 4 de julho de 2012, o Ministério da Educação implementou o Pacto Nacional pela Alfabetização na Idade Certa (PNAIC), em 8 de novembro de 2012. Este pacto é um compromisso formal assumido entre Governo Federal, Distrito Federal, Estados, Municípios e sociedade de assegurar que todas as crianças estejam alfabetizadas até os oito (8) anos de idade, ao final do $3^{\circ}$ ano do Ensino Fundamental. Vale ressaltar que este aspecto de "alfabetizar todas as crianças até no máximo os oito anos de idade" está articulado com a Meta 5 do Plano Nacional de Educação, Lei no 13.005/2014 (BRASIL, 2015).

Assim, o Pacto, aqui entendido como proposta curricular, se constitui por um conjunto integrado de ações, materiais e referências curriculares e pedagógicas disponibilizados pelo MEC, destacando-se quatro eixos de atuação:

1)formação continuada presencial para professores alfabetizadores e seus orientadores de estudo, 2) materiais didáticos, obras literárias, obras de apoio pedagógico, jogos e tecnologias educacionais, 3) avaliações sistemáticas que contemplam as avaliações processuais, debatidas durante o curso de formação e 4) gestão, o controle social e a mobilização (BRASIL, 2015, p. 22).

Conforme o PNAIC, a alfabetização deve ocorrer na perspectiva do letramento, que é o uso da leitura e da escrita em diversas situações sociais, ademais é objetivo da educação formar sujeitos críticos e autônomos. Outra tônica importante do programa é o desenvolvimento do trabalho pedagógico numa perspectiva interdisciplinar, "sem com isso, esquecer as especificidades das áreas do conhecimento e das disciplinas de tradição curricular" (BRASIL, 2015 p. 9).

Ainda conforme o PNAIC, o currículo na alfabetização deve ser desenvolvido em ciclos, "espera-se que, no $1^{\circ}$ ano, as práticas de ensino da leitura e da escrita possibilitem à criança a construção da base alfabética e que os $2^{\circ}$ e $3^{\circ}$ anos sejam destinados à consolidação das correspondências som-grafia por meio de diversas situações significativas" (BRASIL, 2012, p. 16). 
Com isso, o programa define os direitos de aprendizagem para a disciplina de Língua Portuguesa organizados por eixos, quais sejam: Leitura, Produção de textos Escritos, Oralidade, Análise Linguística (BRASIL, 2012).

Para que essa proposta de fato fosse efetivada, a formação continuada de professores tornou-se um ponto nodal. Assim o programa desenvolveu o curso para os professores alfabetizadores com cinco princípios centrais que orientam a concepção dos dez (10) Cadernos de Formação. São esses princípios:

- Perspectiva de um currículo inclusivo, que defende os Direitos de Aprendizagem de todas as crianças, fortalecendo as identidades sociais e individuais;

- Integração entre os componentes curriculares;

- Foco central na organização do trabalho pedagógico;

- Seleção e discussão de temáticas fundantes em cada área de conhecimento;

- Ênfase na alfabetização e letramento das crianças. (BRASIL, 2015, p. 33)

Enquanto a Base Nacional Comum Curricular - BNCC é documento de caráter normativo, contendo 600 páginas. A base define por meio de um conjunto de habilidades e 10 competências de aprendizagens consideradas essenciais que todos os alunos devem desenvolver ao longo das etapas e modalidades da Educação Básica, de modo a que tenham assegurados seus direitos de aprendizagem e desenvolvimento, em conformidade com o que preceitua o Plano Nacional de Educação (BRASIL, 2018). Faremos aqui uma análise crítica da BNCC. Tal perspectiva pode ser identificada nos trabalhos de Macedo (2015; 2014), Uchoa e Sena (2019), Aguiar e Dourado (2018).

Desde 1988 com Constituição Federal, perpassando pela implementação da Lei de Diretrizes e Bases da Educação Nacional (1996) e pela difusão dos Parâmetros Curriculares Nacionais (1997) que o Sistema Nacional de Educação discute sobre uma Base, contudo foi em 2014 com a Lei 13.005/14 que ao promulgar o PNE 2014-2024 estabelecendo-se diretrizes, metas e estratégias que o desejo de tal base se tornou possível. Todos os autores 
críticos à BNCC acreditam que a partir do Golpe de 2016, com o impeachment da Presidente Dilma Roussef, o setor privado ganhou mais forças nas definições das políticas educacionais.

Conforme Dourado e Sena (2019, p. 20) o viés de educação empresarial, pautada pelos princípios das competências e habilidades, eficácia e eficiência, dos indicadores e da avaliação como controle é preocupante haja vista há nesse processo a homogeneização do currículo, o fortalecimento das avaliações padronizadas e controle do financiamento. Assim para esses autores há armadilhas contidas no mote "direitos de aprendizagens".

Segundo Sampaio de Souza e Baptista (2017, p. 6), o termo "aprendizagens essenciais" na BNCC cria um padrão em que o aluno deverá atingir habilidades e competências de uma educação e escola etapista que mais preocupa com avaliações de larga escala ao qual está longe de um projeto cidadã e emancipatório. De fato, isso é no mínimo questionável, pois além de engessar o currículo torna o apolítico e neutro. Uma educação nessa perspectiva é desrespeitosa e alienante por não considerar a realidade sociocultural do sujeito.

De acordo com Sampaio de Souza e Baptista (2017), a perspectiva de linguagem assumida pela BNCC é a do filósofo Mikhail Baktin, em que a linguagem é entendida como interação, ou seja, a língua é viva e não pode ser desassociada do seu contexto ideológico. No entanto, "é necessário garantir que na prática escolar e no trabalho diário, essa concepção seja de fato aplicada ao ensino" (SAMPAIO DE SOUZA; BAPTISTA, p. 8).

Nesse documento, o ensino fundamental está dividido em cinco áreas do conhecimento, sendo que o componente curricular de Língua Portuguesa está presente na área de Linguagens. O componente Língua Portuguesa da BNCC dialoga com documentos e orientações curriculares produzidos nas últimas décadas, como por exemplo os Parâmetros Curriculares Nacionais - PCNs e as Diretrizes Curriculares Nacionais - DCNs.

Esse componente curricular proposto pela BNCC proporciona aos estudantes experiências que contribuam para a ampliação dos letramentos, de forma a possibilitar a participação significativa e crítica nas diversas práticas sociais permeadas/constituídas pela oralidade, pela escrita e leitura e por outras linguagens (BRASIL, 2018, p. 67-8). 
As práticas de linguagens, objetos de conhecimentos e habilidades nos anos iniciais são definidas por quatro eixos. Assim diz o documento:

No eixo Oralidade, aprofundam-se o conhecimento e o uso da língua oral, as características de interações discursivas e as estratégias de fala e escuta em intercâmbios orais; no eixo Análise Linguística/Semiótica, sistematiza-se a alfabetização, particularmente nos dois primeiros anos, e desenvolvem-se, ao longo dos três anos seguintes, a observação das regularidades e a análise do funcionamento da língua e de outras linguagens e seus efeitos nos discursos; no eixo Leitura/Escuta, amplia-se o letramento, por meio da progressiva incorporação de estratégias de leitura em textos de nível de complexidade crescente, assim como no eixo Produção de Textos, pela progressiva incorporação de estratégias de produção de textos de diferentes gêneros textuais. (BRASIL, 2018, p. 89)

Este documento ainda deixa claro que a alfabetização nos anos inicias $\left(1^{\circ}\right.$ e $2^{\circ}$ ano) deve ser o foco da ação pedagógica, pois espera-se que os estudantes conheçam o alfabeto e a mecânica da leitura/escrita.

No âmbito municipal, no nível mesmo, por meio da Secretaria Municipal de Educação, há uma recontextualização dos documentos nacionais por meio do Plano Municipal de Educação (PME). No artigo $2^{\circ}$, inciso I do Plano Municipal de Educação a proposta é a erradicação do analfabetismo. Esse documento ainda recontextualiza as Diretrizes Curriculares Nacionais para a Educação Escolar quilombola ao passo que define no artigo $2^{\circ}$, inciso III, a superação das desigualdades educacionais, com ênfase na promoção da cidadania e na erradicação de todas as formas de discriminação.

Considerando as modalidades de educação diferenciada, o artigo $7^{\circ}$, no parágrafo $4^{\mathrm{o}}$, contempla que

Haverá regime de colaboração específico para a implementação de modalidades de educação escolar que necessitem considerar territórios étnico educacionais e a utilização de estratégias que levem em conta as identidades e especificidades socioculturais e linguísticas de cada comunidade envolvida, assegurada consulta prévia e informada a essa comunidade. (VITÓRIA DA CONQUISTA, 2015, p. 17) 
Ainda sobre as relações étnicas, o Plano Nacional de Implementação das Relações Etnicorraciais orienta os sistemas de ensino e as instituições educacionais na implementação das Leis 10639/2003 e 11645/2008 (BRASIL, 2003; 2008) e as Diretrizes Curriculares Estaduais para a Educação Escolar Quilombola (RESOLUÇÃO No 68 de 30 de julho de 2013) estabelece normas complementares para implantação e funcionamento das Diretrizes Curriculares Nacionais para a Educação Escolar Quilombola na Educação Básica (BAHIA, 2013).

Sobre a política de alfabetização, o Plano Municipal de Educação de Vitória da Conquista propõe na meta 5 alfabetizar todas as crianças, no máximo, até o $3^{\circ}$ (terceiro) ano do ensino fundamental. Dentre várias estratégias dessa meta, uma se destaca pensando a Educação Escolar Quilombola:

Assegurar a alfabetização de crianças do campo, indígenas, quilombolas e de populações itinerantes, com a produção de materiais didáticos específicos, e desenvolver instrumentos de acompanhamento, que considerem o uso da língua natural usada pelas comunidades indígenas e a identidade cultural das comunidades quilombolas. (PME, 2015, p. 17)

Visualizamos em quase todas as metas, desde a meta 2, que diz sobre o ensino fundamental, a meta 4 sobre a educação especial, a meta 5 , como já foi citada sobre a política de alfabetização, a meta 7 sobre a qualidade de educação até a meta 15-18 sobre a valorização dos profissionais da educação definições de estratégias para a Educação Escolar quilombola, embora não as tenhamos identificadas nas práticas da professora durante o tempo de permanência na EQJA.

O plano anual de curso do município de Vitória da Conquista está de acordo com que propõe a BNCC, estabelecendo, portanto, os objetos de conhecimento, as habilidades e as expectativas de aprendizagem (objetivos). Na disciplina de Língua Portuguesa, para o primeiro trimestre (15/ 03 a 14/06) está proposto que se trabalhe com os eixos de oralidade, escrita, conhecimentos linguísticos e gramaticais, leitura, educação literária.

Com isso, percebemos que há uma recontextualização dos documentos oficiais nacionais (contexto macro) para os documentos municipais (contexto meso). Nesse sentido, 
o campo recontextualizador é importante para "a seleção de textos que vai do campo intelectual criado pelo sistema educacional para os campos de reprodução daquele sistema" (BERNSTEIN, 1996, p. 89-90). Nesse processo de deslocação e relocação, o discurso original passa por uma transformação: de uma prática real para uma prática imaginária em que o discurso é sempre transformado ou modificado, que é o que passaremos a visualizar no próximo tópico, no contexto micro, reconhecido também como campo recontextualizador pedagógico.

\section{O campo recontextualizador pedagógico}

Neste item demonstramos como os conteúdos de Língua Portuguesa são deslocados do nível macro para o nível micro, ou seja, como se efetiva a sua recontextualização. Para a caracterização da prática pedagógica, utilizamos um protocolo estruturado com 7 (sete) categorias: a) fronteiras de espaços entre alunos e professores; b) relações de comunicação; c) critérios de avaliação; d) ritmos de aprendizagem; e) relações intradisciplinares; f) nível de exigência conceitual; e g) nível de proficiência investigativa.

Ao falar das fronteiras de espaços de entre alunos e professores, destaca-se os limites das vozes desses sujeitos, ou seja, a delimitação dos papéis desempenhados por eles dentro do processo de comunicação intraescolar, a participação dos agentes nas escolhas e no encaminhamento das atividades ao longo da aula, situações de indisciplina. Essa categoria tem a ver com o que Bernstein (1996) chamou de voz.

$\mathrm{Na}$ relação de comunicação são analisados aspectos que dizem respeito à efetividade da interação ente professores e alunos durante a aula, a natureza dos diálogos, frequência de realização de perguntas e suas respectivas respostas, as diferentes linguagens pedagógicas que são utilizadas pelo professor durante a aula. Essa categoria condiz com o que Bernstein (1996) chamou de mensagem.

$\mathrm{Na}$ categoria critérios de avaliação consideramos a maneira como a professora expõe aos alunos os critérios de validação dos textos, sua forma de realizar correções durante aula, a legitimidade dada (ou não) aos saberes consensuais que são partilhados pelos estudantes e trazidos para o contexto da sala de aula. 
Dentro da categoria ritmos de aprendizagem será analisada a frequência com que ocorrem interrupções durante a aula para que algum conceito ou atividade seja retomado, a maneira como são oferecidas (ou não) atividades paralelas de fixação e aprofundamento para aqueles alunos que apresentam mais dificuldades.

Dentro da categoria relações intradisciplinares serão analisadas o grau de relação entre diferentes conteúdos bem como a exploração de diferentes pontos de vista sobre as questões trabalhadas pela professora e a problematização gerada pelo processo.

No âmbito da categoria nivel de exigência conceitual são destacados aspectos referentes à exploração de modelos científicos, conceitos e generalizações, níveis de interesse e disposição dos estudantes para o debate e a elaboração do conhecimento.

Sobre a categoria nivel de proficiência investigativa destacam mecanismo de estímulo para o aluno buscar informações por conta própria (ou não), o grau de problematização das atividades oferecidas e se ocorrem exercícios de construção de explicação a partir de diferentes métodos investigativos.

Todas essas categorias têm valores mais explícitos ou menos explícitos, desencadeando numa pedagogia visível ou invisível (BERNSTEIN, 1966). Essas definições podem ser compreendidas também como currículo de coleção ou currículo de integração.

\section{Sobre as fronteiras de espaços entre alunos e professores}

Esta categoria reúne elementos específicos de regulação da comunicação no interior da aula em que se evidenciam os papéis (ou vozes) de professores e alunos, correspondendo, portanto, aos princípios de classificação, ou seja, são os conteúdos determinados pela professora.

As regras hierárquicas “estabelecem as condições para a ordem, o caráter e os modos de comportamento", (BERNSTEIN, 1996, p. 97) os papéis de transmissor e adquirente são nelas determinados.

Segundo Bernstein (1996, p. 80), essas regras podem ser explícitas ou implícitas, ao passo que quando as regras são explícitas, a base de poder da relação social é visível e sem 
disfarces. Contrariamente, quando essas regras são implícitas, a base de poder da relação social é mascarada, ocultada, obscurecida, por estratégias de comunicação.

As observações demostraram que essa categoria tende a ser fortemente delimitada, uma vez que os encaminhamentos das aulas eram conduzidos pela professora, porém com diálogos e com tolerância baixa à casos de indisciplina, como vemos o trecho a seguir:

O conteúdo que a professora anuncia que irá trabalhar é o dezenove de abril, dia do índio. Ela liga a televisão e passa um vídeo sobre os índios, dizendo para as crianças que elas precisam prestar atenção. Todos assistem atenciosamente. Quando alguém tenta conversar a professora fala: "vamos escutar!" e as crianças obedecem. (Caderno de campo, aula 26 de abril de 2019)

Em outro momento, no mesmo dia, registramos no diário de campo:

[Os alunos começam a conversar e professora lhes chama atenção para voltar a participar da aula].

Prof.: quais os instrumentos musicais que os índios usavam?

Alunos: tambor, gaita, guitarra...

Prof.: guitarra não! [E parabeniza o aluno que falou gaita].

[Pergunta quais os instrumentos que os índios utilizavam para caçar, os alunos respondem: "arco e flecha"].

Pergunta o que os índios utilizavam para ficarem bonitos. Os alunos não sabem responder. começa uma discussão sobre a utilização do barro.

Pires, Morais e Neves (2004), pesquisadoras portuguesas do grupo ESSA (Estudos Sociológicos da Sala de Aula $)^{1}$ afirmam que para promover um elevado nível de desenvolvimento científico essa categoria deve ter classificação fraca entre os espaços, de modo que os alunos tenham autonomia para definir temáticas do seu interesse e relacionadas às suas realidades socioculturais. No contexto de nossa pesquisa, os conteúdos eram determinados pela professora e ela levava em consideração as datas comemorativas e o que está previsto no documento da BNCC, indicando nesse sentido, um currículo de coleção.

\footnotetext{
${ }^{1}$ Constitui um grupo de investigação integrado na UIDEF (Unidade de Investigação, Desenvolvimento e Formação) do Instituto de Educação da Universidade de Lisboa e que pretende valorizar a perspectiva sociológica na análise da educação pesquisando particularmente nas áreas das ciências.
} 


\section{Sobre as relações de comunicação}

As relações de comunicação reúnem elementos específicos de regulação da comunicação no interior da aula, correspondendo à mensagem, o que Bernstein (1996) considera como enquadramento, podendo ser mais explícitos ou menos explícitos.

No contexto de nossa pesquisa, visualizamos que as relações de comunicação tendiam a ser abertas, ao passo que os alunos participavam das aulas sob a indução da professora, visto que na medida em que ela perguntava, eles respondiam, como podemos ver no trecho a seguir:

Prof.: vamos ler - [e ler pausadamente a palavra inferno. Depois ela escreve no quadro e as crianças vão falando letra por letra].

Prof.: quantas sílabas gente?

Alunos: 3

Prof.: quantas letra gente? [eles contam]

Alunos: 7

[Nesse momento a professora fala da importância dos números. Escreve a palavra céu falando "apenas" que tem que ter o acento].

Prof.: quantas sílabas?

Alunos: uma

Prof.: quantas letra?

Alunos: 3

[A professora escreve o nome "amarelinha" no quadro contando as letras " 10 " e as sílabas " 5 ". Se direciona para uma criança (M), e pergunta quantas sílabas: "eu vou falando (e batendo palmas) e você vai contando" assim ele faz e responde]. (Caderno de campo, aula 24 de abril de 2019)

Pires, Morais e Neves (2004, p. 20) sinalizam que para haver a aprendizagem "a relação deve ser aberta entre professor e seus alunos e entre aluno-aluno, neste caso o enquadramento fraco". Conforme Stefenon (2017, p. 136), o professor assume um papel central na determinação da flexibilização dessas fronteiras e no estabelecimento de uma postura aberta no processo comunicativo de modo que os alunos tenham uma maior participação.

Os alunos sempre recorriam à professora para tirar dúvidas sobre as atividades, principalmente os do $2^{\circ}$ ano; ela os auxiliava à medida que podia, pois sempre estava ocupada ensinando algum discente do $1^{\circ}$ ano. 
Durante as aulas observamos que foram exploradas diferentes linguagens didáticas, principalmente a oralidade, escrita e leitura. Dessa forma, a professora segue ao que está proposto na meta 5 no que se refere à política de alfabetização do Plano Municipal de Educação de Vitória da Conquista, bem como segue o plano anual quando o foco do seu trabalho é a alfabetização, o que caracteriza como pedagogia visível. Em conversas informais, ela sempre se mostrava preocupada em alfabetizar as crianças até o final do ano. Entretanto, no que diz respeito à produção de materiais específicos para a educação escolar quilombola previsto na estratégia 5.7 na sua prática não acontece, ademais o livro didático que a escola tem é trabalhado por toda a rede de educação e as atividades que ela retirava da internet não considerava essa temática.

\section{Sobre os critérios de avaliação}

As regras de avaliação são os critérios que se esperam que o adquirente aprenda para se aplicar ou não diante de uma dada situação, nessa perspectiva a competência do adquirente é avaliada. "Essa avaliação baseia-se nas condutas, caráter, modos de comportamento (critérios regulativos) ou resolução de um problema ou produção de um segmento de escrita/fala (critérios instrucional/discursivo)” (EUGÊNIO, 2009, p. 48).

Tais regras se manifestam explicitamente ou implicitamente: "Quando as regras são explícitas, os critérios a serem transmitidos são explícitos e específicos, enquanto que quando elas são implícitas, os critérios a serem transmitidos são implícitos, múltiplos e difusos" (BERNSTEIN, 1996, p. 81).

Considera-se necessário que no âmbito da escola os critérios sejam explicitamente informados no processo da comunicação pedagógica a fim de oferecer maior clareza ao aluno sobre aquilo que se espera de seu desempenho durante as ações desenvolvidas.

Percebermos que na escola pesquisada esses critérios se apresentam explícitos, na medida que a professora deixa claro que quer que os alunos aprendam a ler e escrever cobrando dos mesmos atenção para que consigam resolver essas as atividades.

Volta para o primeiro grupo do $1^{\circ}$ ano e pergunta: se a sereia fosse mãe, seria mãe de quem? Alunos: peixe 
Prof:: com que letra começa

Aluno: P-A

Prof.: é paixe?! [E fala que é a letra E que se coloca, e vai colocando as outras letras com os alunos sempre participando, mesmo que de forma errada, o que leva a professora a corrigi-los. Vai para

o segundo grupo]

Prof.: todos concordam que a sereia poderia ser a mãe dos peixes?

Alunos: sim

Prof.: como se escreve?

Aluno: $P$

Prof.: mais o que?

Aluno: A

Prof.: ah é paixe

Outro aluno: I

Prof:: ah é piixe

[A professora vai instigando os alunos e eles vão participando. No lugar do x um aluno pede para colocar o R. A professora lhe questiona: ah seria peire? A professora o corrige e lê silabicamente].

(Caderno de campo, aula 08 de maio de 2019)

Vemos nessa situação que professora corrige os alunos e os auxilia, falando que dependendo da letra que coloca muda o sentido da palavra. Para que ocorra um processo de aprendizagem efetiva os critérios de avaliação devem ser explícitos, ou seja, com enquadramento forte, segundo Pires, Morais e Neves (2004) caracterizando assim como a ocorrência da especificação do que é cobrado e esperado que realizem ao longo da aula.

\section{Sobre relações intradisciplinares}

Esta categoria, juntamente com a exigência conceitual e proficiência investigativa fazem referência direta ao conteúdo das mensagens comunicadas durante a prática pedagógica. A intradisciplinaridade é interação de uma atividade ou conteúdos entre diferentes saberes da mesma área.

Percebemos na prática da professora Ivani durante as aulas que o trabalho com a oralidade, escrita e leitura se davam de forma inter e intradisciplinar ao efetivar o currículo de Língua Portuguesa, isso porque ela buscava realizar relações entre diferentes conteúdos, e disciplinas explorando um pouco diferentes pontos de vistas sobre determinados assuntos, como evidenciamos a seguir sobre a intradisciplinaridade ao falar de vários gêneros textuais: 
Fala que quarta feira será a comemoração do dia das mães e que ela mandará um recado para os seus pais, que é outro tipo de gênero textual além do bilhete. (conteúdo da aula)]

Prof.: oh gente, quando eu vou fazer uma festa eu mando o que?

Alunos: convite

Prof.: oh eu tenho outro tipo de comunicação. - [e mostra um trecho de um poema de Mario Quintana, falando que é um cartão. E indaga:]

Prof.: "estamos trabalhando o que?"

Alunos: bilhete. (Caderno de campo, 09 de maio de 2019)

Nesta aula, trabalhando sobre a comemoração do dia das mães a professora explorou sobre os gêneros textuais, explicou o que é bilhete e falou da sua diferença com o poema, "que este ler cantando".

Para que se efetive a aprendizagem é imprescindível que ocorram fortes relações intradisciplinares (classificação fraca entre os vários conteúdos das disciplinas), conforme apontam os estudos desenvolvidos pelo Grupo Estudos Sociológicos da Sala de Aula, a exemplo de Pires, Morais e Neves (2004). Segundo Stefenon (2017), nesse caso há maior flexidade entre os conteúdos e conexões mais amplas entre as diferentes temáticas. $\mathrm{Na}$ prática da professora Ivani essas relações tendiam a fracas, uma vez as que as disciplinas do seu planejamento dialogavam com o que entendemos como interdisciplinaridade. Essa relação se mostrou muito forte com a disciplina de Ciências, como podemos ver no excerto abaixo:

[Escreve a palavra CAVALO no quadro e vai lendo silabicamente. Depois ela fala para não lê uma sílaba Só, "para falar a palavra completa" e volta a ler as sílabas e pergunta que palavra é].

Aluno: Lorena.

[A professora sorri e volta retomando cada sílaba da palavra, tentando fazer com que os alunos recuperem o sentido da palavra cavalo. Pede para falar rápido" CA-VA-LO”. Algumas crianças recuperam o significado. Um aluno não recupera o significado e pergunta a professora que palavra é, ela responde].

[Na palavra MULHER a professora fala que essa é mais difícil e mostra falando e escrevendo no quadro a sílaba LHER. E retoma a palavra]:

Prof:: "MU com LHER" [e as crianças respondem: "mulher"]. (caderno de campo, 23 de maio de 2019)

Como vemos nesse episódio da aula de Ciências sobre os seres vivos, a professora explora o conteúdo de consciência fonológica, escrevendo os nomes no quadro. Nessa 
relação, vimos que a professora trabalha na perspectiva letramento, o que torna possível fazer tal interdisciplinaridade. Essas características se aproximam da pedagogia invisível.

\section{Sobre os níveis de exigência conceitual}

O nível de exigência conceitual diz respeito à exploração da linguagem e modelos científicos, bem como a realização de generalizações e de reflexões em torno de conceitos.

Em nossa pesquisa verificamos que o nível de exigência conceitual tendia a ser baixo, pois as aulas apresentam, na maior parte do seu tempo, encaminhamentos e posturas que se relacionam com atividades descritivas e mecânicas.

A professora chama os alunos do $1^{\circ}$ ano para ler. A maioria dos alunos não conseguem ler. Quando chama uma aluna que sempre está dispersa para ler, em poucos instantes manda a menina sentar e fala irritada que todos ficarão sem recreio, estudando e fala para a menina: "olha, estou olhando para você!" e que só três alunos conseguiram ler algumas palavras. A professora lê novamente o texto, os alunos começam a repetir e ela fala "que não é assim que se aprende a ler, que tem que ver e ouvir".

Outra aluna fala que ela já sabe ler. A professora a manda ler e a menina faz uma pseudoleitura. A professora sorri e fala que a imaginação saiu, eu dou risada e falo que fluiu. A professora manda outros alunos leem e passam a aceitar a pseudoleitura. Quando manda a outra menina ler novamente, esta se mostra resistente e permanece calada. (Caderno de campo, aula 09 de maio de 2019)

Em algumas vezes a professora solicitava aos alunos do $1^{\circ}$ ano que lessem, esperando que eles conseguissem. Como os alunos demonstravam ainda não terem adquirido o processo da leitura, ela parecia frustrada. A docente sempre comentava que tem aluno do pré-escolar melhor do que alguns meninos dessa turma da tarde.

De acordo com Pires, Moraes e Neves (2004), para que haja uma melhor aprendizagem é necessário um elevado nível conceitual, ou seja, uma maior exploração da linguagem, elaboração de generalizações e conceitos, bem como interesse pelas atividades.

Apesar de os alunos apresentarem muitas dificuldades na aquisição da leitura e escrita, eles eram muito participativos, como podemos observar no excerto abaixo:

[Um aluno do segundo ano pergunta o que é para desenhar e a professora fala que é para desenhar as brincadeiras que ele mais gosta. Ela vai até sua cadeira e pergunta se vai fazer só um desenho, a criança responde que não e a professora replica: "então ande logo porque o tempo está passando”. O aluno chama a professora, pois está com dúvidas]. 
Prof.: as brincadeiras parecem com as de sua escola?

Aluno: não

Prof.: então escreva não

Aluno : eu não sei escrever

Prof.: não acredito que você não sabe escrever a palavra não?! Escreva a letra N. [a professora vai mandando ele escrever letra por letra]. (Caderno de campo, aula 24 de maio de 2019)

$\mathrm{Na}$ entrevista, perguntamos a professora de que forma ela trabalha com aqueles alunos que apresentam mais dificuldades, e assim ela nos respondeu que:

O correto é você trabalhar corpo a corpo com o aluno, sentar junto com o aluno mesmo, oh, e.. e, e estar ali trabalhando junto com ele, tentando, mostrando para ele, por exemplo, eu descobri uma estratégia maravilhosa, que é você trabalhar com o alfabeto móvel, para aquela criança que ainda não sabe ler, só que você tem que trabalhar com um ou dois no máximo, porque senão você não consegue porque você tem que trabalhar com ele construindo as hipóteses da escrita e da leitura, entendeu? como é que você vai fazer essa construção junto com essas hipóteses com a sala cheia, você não consegue porque uns prestam atenção outros não. Se você deixar o alfabeto lá com uma dupla e você for trabalhar com outro, você pode ver ele para, então tinha que ser.. assim por exemplo, é.. hoje a aula iniciou sobre meio ambiente, ne, então poderíamos destacar a palavra natureza, por exemplo, eles não vão saber escrever a palavra NATUREZA de forma livre, então você coloca o alfabeto móvel, e ai você tem que ficar lá sentado, olhando ele fazer a montagem das letras, quais as hipóteses que ele consegue já realizar, ai se ele não consegui, ai você tem que questionar, você não pode falar: não tira esse aqui e põe esse aqui não, você tem que questionar: oh você não acha que essa letra não ficaria melhor em outro lugar? vamos trocar ai de lugar para ver? vamos ler? como é que ler essa palavra aqui do jeito que você colocou ai, ne. Aí lê, aí descobre que o som é diferente da palavra que se quer, vamos trocar ai de lugar para ver. É isso que tem que ser feito no processo, com o menino na alfabetização, é você construir as hipóteses junto com ele, ele está construindo e você observando porque se você deixar ele sozinho, ele não

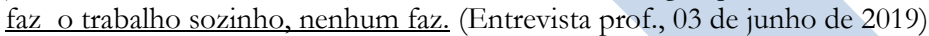

A professora acredita que trabalhar individualmente ou com pequenos grupos a aprendizagem se torna mais eficiente. Nas aplicações das atividades, a professora tenta desenvolver um trabalho mais individualizado, de modo que forma pequenos grupos para ir orientando as crianças. Podemos constar isso no trecho abaixo.

[A professora vem auxiliar uma, pergunta a menina como ela escreveu a palavra "estrela", e que não era para ela copiar, porque é para ela aprender]. A professora fala: ah você copiou pela atividade da colega, ela esqueceu de copiar o "E" e você fez do mesmo jeito. [Assim ela apaga onde a menina errou e escreve as letras que faltavam].

Alguns alunos do $2^{\circ}$ vão até a professora pedir orientação e ela ajuda quando pode. Ela chama um aluno atenção, para ele se esforçar que ele quer que ela escreve para ele e que isso ela não irá fazer.

A professora volta a fazer outra pergunta para o primeiro grupo do $1^{\circ}$ ano: 
Prof.: se a mesa fosse mãe seria mãe das?

Alunos: cadeira

A professora pega as letras caixa e forma o nome cadeira. Pergunta a primeira e a última letra e a quantidade de sílabas e os alunos respondem.

Ela volta a orientar o segundo grupo do $1^{\circ}$ ano, faz a pergunta voltada para uma aluna. A menina responde "mesa", a professora pergunta novamente e ela responde "cadeira". A professora começa a montar a palavra.

Prof:: cadeira começa com que letra?

Alunos: C

A professora vai falando silabicamente e perguntando as letras. Os alunos vão falando. A professora pergunta quantas sílabas e quantas vogais há nas palavras exploradas. Manda-os escreverem a palavra e passa para o terceiro grupo.

Prof.: o CA é formado por quais letras?

Alunos: $\mathrm{C}$ e A.

A professora continua trabalhando fonético e fonologicamente as palavras.

A turma faz um pouco de barulho e professora sempre pede silêncio. (Caderno de campo, aula 24 de maio de 2019)

No trecho acima, sobre a semana do "dia das mães", a professora trabalha com suposições, que se os "objetos fosse mãe, de quem eles seriam". Naquele momento os alunos recebiam o alfabeto móvel e tentava montar a palavra. No entanto, eles não conseguiam fazer a atividade sozinhos, o que exigia da professora montar pequenos grupos e ir montando as palavras juntamente com eles. Dessa forma, é possível visualizar o processo de recontextualização presente na prática da professora na disciplina de língua portuguesa uma vez que o foco nos anos inicias de acordo com os documentos oficiais é alfabetizar e letrar as crianças.

\section{Sobre proficiência investigativa}

O nível de proficiência investigativa refere-se à problematização, reflexividade e autonomia dos estudantes diante da prática pedagógica promovida pela professora. Verificamos no contexto de nossa pesquisa que os alunos geralmente por meio de perguntas e respostas nas aulas elaboravam tímidos movimentos para a formulação de hipóteses, principalmente na construção de palavras, apresentando nesse sentido um nível de proficiência baixo, de acordo com os relatos abaixo. 
[Escreve a palavra CAVALO e vai lendo silabicamente. Depois ela fala que não ler uma sílaba uma sílaba Só, "para falar a palavra completa" e volta a ler as sílabas e pergunta que palavra é].

Aluno: Lorena

[A professora sorri e volta retomando cada sílaba da palavra, tentando fazer com que os alunos recuperem o sentido da palavra cavalo. Pede para falar rápido CA-VA-LO. Algumas crianças recuperam o significado. Um aluno não recupera o significado e pergunta a professora que palavra é, ela responde]. (Aula 23 de maio)

Os alunos do $1^{\circ}$ ano não conseguem ler sozinhos e também nem todos do $2^{\circ}$ ano não conseguem recuperar o significado das palavras lidas silabicamente. Para se realizar uma aprendizagem significativa Pires, Morais e Neves (2004) sinaliza a promoção de um elevado nível de competência investigativa, de modo que os alunos mantenham uma postura crítica, reflexiva e autônoma.

\section{Sobre os ritmos de aprendizagem}

Conforme Bernstein (1996), os ritmos de aprendizagem dizem respeito ao tempo que se efetiva a prática pedagógica. Assim, os ritos se estruturam determinando o compassamento da prática pedagógica à medida que a professora para a aula para explicar melhor determinado assunto quando alguém não entendeu, quando são oferecidas atividades paralelas, quando inicia e termina a aula.

Com isso, buscamos visualizar as regras de sequenciamento, entendidas como a transmissão do que vem antes e depois, havendo nesse sentido uma progressão. Dentro dessas regras de sequenciamento, tem as regras de compassamento que "é o tempo, permitido para se cumprir as regras de sequenciamento" (BERNSTEIN, p. 97), ou seja, é a ritmagem da aquisição.

Quando essas regras são explícitas, os princípios e os sinais de transmissão são esclarecidos e tornado públicos. Em contrapartida, quando essas regras são implícitas, os princípios e sinais da progressão são conhecidos apenas do transmissor. Essas duas regras determinam respectivamente o que o educando pode ou não ter conhecimento do que se está transmitindo (BERNSTEIN, 1996, p. 81).

No contexto de nossa pesquisa embora não existam atividades paralelas, visualizamos que os ritmos de aprendizagem tendem a ser fracos, de modo que as aulas e atividades 
eram brevemente interrompidas, retomadas ou apresentadas de outra maneira para que fosse refeitas por aqueles que apresentavam alguma dificuldade de aprendizagem, considerando os múltiplos ritmos de aprendizagem de cada aluno, conforme o relato abaixo:

L chama a Prof.: professor você me deu a tarefa errada"

Prof.: a tarefa é essa mesma.

Outro aluno: a tarefa de L é do $1^{\circ}$ ano. (L está no $2^{\circ}$ ano)

Prof.: L não consegue acompanhar a tarefa do $2^{\circ}$ ano, por isso vai fazer a tarefa do $1^{\circ}$ ano. (aula 26 de maio)

[A professora volta a perguntar por que o texto é um poema. As crianças não sabem responder e explica:]

Prof:: é um poema porque a gente lê diferente, lê cantando os versinhos.

Aluna: o que é um versinho?

Prof.: verso é esse versinho (vai até a cadeira da menina e mostra). (aula 26 de maio)

A professora organiza o material e fala: oh $\mathrm{D}$, você perguntou se vamos terminar a tarefa de ontem, vamos terminar agora. (Caderno de campo, aula 08 de maio de 2019)

Contudo, não eram apresentadas atividades paralelas, a não ser as atividades para casa que era passadas quase todos os dias. De acordo com Pires, Morais e Neves (2004), para que haja a promoção do conhecimento há que haver um fraco ritmo de aprendizagem (enquadramento fraco), ou seja, uma maior flexibilização do tempo, bem como a frequência em que o professor retoma o conteúdo e a aula para melhor explicação.

De acordo com os trechos das aulas acima, concluímos que há uma flexibilização do tempo abrindo espaço para os alunos participarem, retoma os conteúdos frequentemente, e por algumas vezes passam atividades do $1^{\circ}$ ano para aqueles alunos do $2^{\circ}$ ano para aqueles que têm mais dificuldades de responder. Como havia dito anteriormente, isso são características de um ritmo de aprendizagem fraco, o que contribui para a aprendizagem. Como essas regras estão claras, a pedagogia é visível.

\section{Considerações finais}

As contribuições da teoria do dispositivo pedagógico mostraram-se fundamentais para desvelar como o currículo na disciplina de Língua Portuguesa é recontextualizado na prática pedagógica de uma professora em uma turma multisseriada de $1^{\circ}$ e $2^{\circ}$ ano do ensino fundamental de uma escola quilombola. 
Nas observações em sala de aula, a docente apontou que é muito desafiador trabalhar como uma turma multisseriada. Relatou também que a turma tem muitas dificuldades, de modo que ela não prioriza o livro didático, pois para ela este muitas vezes não o contempla.

As categorias adaptadas de Stefenon (2017) nos possibilitaram caracterizar a transmissão-aquisição do conhecimento proposto no nível macro para o nível micro. Para isso visualizamos que no nível macro no âmbito nacional o Pnaic e a BNCC propõe a alfabetização e o letramento, no nível meso no âmbito municipal essa proposta não destoa e a professora no contexto micro busca alfabetizar e letrar seus alunos.

Detendo-nos sobre as práticas curriculares, vemos que na categoria fronteiras entre espaços de alunos e professores as regras são explícitas, caracterizando assim como pedagogia visível. Na categoria de comunicação, embora seja aberta, o controle está com a professora, e os alunos sabem dessa determinação, o que caracteriza como uma pedagogia visível.

Nas categorias critérios de avaliação e ritmos de aprendizagem, há indícios de uma pedagogia visível, uma vez que a comunicação está clara tanto para o aluno, como para a professora. Por outro lado, as relações intradisciplinares se despontaram tendendo a fraca, o que significa que os conteúdos não estão isolados, apresentado nesse viés elementos que aproximam da pedagogia invisível. Esse contexto, segundo Pires, Morais e Neves (2004), é favorável para aprendizagem.

Ainda como pedagogia invisível destacaram as categorias nível de exigência conceitual e nível de proficiência investigativa, pois as crianças sentiam muitas dificuldades para realizar as atividades, de modo que principalmente os alunos do $1^{\circ}$ ano não tinham nenhuma autonomia para realizar as tarefas sozinhos; caso a professora não os acompanhasse, eles não realizavam as atividades propostas.

Sobre a escola estar situada numa comunidade quilombola, vimos uma prática distante do que está proposto nas Diretrizes Curriculares Nacionais para a Educação Escolar Quilombola, uma vez que não trabalha com materiais específicos e por abordar a realidade sociocultural das crianças de forma incipiente. Desse modo predominou se uma pedagogia 
visível que é aquela que se relaciona com o código elaborado, compreendido também como currículo de coleção.

Contudo, há indícios de uma pedagogia invisível visto que o currículo de Língua Portuguesa se apresenta como de integração, na medida em que o trabalho com as disciplinas se dialogam, de outro modo, há permeabilidade entre as áreas do conhecimento como tangencia Bernstein (1996).

\title{
RECONTEXTUALIZATION OF PORTUGUESE LANGUAGE CURRICULUM IN A CLASSROOM OF A QUILOMBOLA SCHOOL
}

\begin{abstract}
This article presents the results of an ethnographic research, through observations, interviews and documentary analysis, whose objective is to analyze the process of recontextualization in the discipline of Portuguese Language in a multiseriate class of 1 st and 2 nd years of elementary school in a quilombola school located in the community of Baixão, located in the municipality of Vitória da Conquista. For the analysis of the data, we used the sociological theory of Bernstein (1996), paying particular attention to the official and pedagogical recontextualizing fields. The teacher's curriculum practice shows evidence that allows her to be seen as a visible pedagogy.
\end{abstract}

KEYWORDS: Recontextualization. Portuguese Language Teaching. Quilombola School Education. Curriculum

\section{REFERÊNCIAS}

ALFERES, Marcia Aparecida; MAINARDES, Jefferson. A recontextualização do Pacto Nacional pela Alfabetização na Idade Certa - PNAIC: uma análise dos contextos macro, meso e micro. Currículo sem Fronteiras, v. 18, n. 2, p. 420-444, maio/ago. 2018.

AGUIAR, Márcia Ângela da S; DOURADO, Luiz Fernandes. A BNCC na contramão do PNE 2014-2024: avaliação e perspectivas. Recife: ANPAE, 2018.

ANGROSINO, Michel. Etnografia e observação participante. Porto Alegre: Artmed, 2009.

BERNSTEIN, Basil. A estruturação do discurso pedagógico: classe, códigos e controle. Vozes: Petrópolis, 1996.

BEZERRA, Debora Silveira Barros. As regras da prática pedagógica no currículo de ciências e língua portuguesa na educação de jovens e adultos. 180f. 2018. Dissertação (Mestrado em Ensino). Universidade Estadual do Sudoeste da Bahia,Vitória da Conquista, 2018.

BRASIL. Resolução nº 8, de 20 de novembro de 2012. Brasília: CNE/CEB, 2012. Disponível em: http://www.seppir.gov.br/portal-antigo/arquivos-pdf/diretrizes-curriculares. Acesso em 07 de agosto de 2018. 
. Parâmetros curriculares nacionais: língua portuguesa. Secretaria de Educação Fundamental. Brasília, 1997.

. Portaria no 867, de 4 julho de 2012. Ministério da Educação. Diário Oficial da União, seção 1, Brasília, 2012.

EUGENIO, Benedito. Políticas curriculares para o ensino médio no estado da Babia: permeabilidades entre contextos e a cultura da escola. 200f. Tese (Doutorado em Educação). Faculdade de Educação, Universidade Estadual de Campinas, Campinas, 2009.

Práticas curriculares em uma escola de ensino médio no estado da Bahia. Educação, Santa Maria, v. 42, n. 1, p. 57-72, jan./abr. 2017.

ESSA, Estudos sociológicos da Sala de Aula. O que é. Resumo (Site oficial). Lisboa. Disponível em: http://essa.ie.ulisboa.pt/oquee_resumo_texto.htm. Lisboa: 2019.

GALLIAN, Claudia Valentina Assumpção. A recontextualização do conbecimento científico: o desafio constitucional do conhecimento científico. 2009. Tese (Doutorado em Educação). Faculdade de Educação, Pontifícia Universidade Católica de São Paulo, São Paulo, 2009.

GEERTZ, Clifford. A interpretaşão das culturas. 1. ed., 13 reimpr. Rio de Janeiro: LTC, 2008.

LIMA, Vivian Ingridy de Carvalho. Raízes, frutos e tramas: pertencimentos, relações étnicas e saberes na comunidade do Baixão. 124f. Dissertação (Mestrado em Relações Étnicas e Contemporaneidade). Universidade Estadual do Sudoeste da Bahia, Jequié, 2018.

MACEDO, Elizabeth. Base Nacional Curricular Comum: novas formas de sociabilidade produzindo sentidos para educação. Revista e-Curriculum, São Paulo, v. 12, n. 03 p. 1530 1555 out./dez. 2014.

. Base Nacional Comum para currículos: direitos de aprendizagem e desenvolvimento para quem? Educ. Soc., Campinas, v. 36, nº.133, p. 891-908, out./dez. 2015

MAINARDES, Jefferson; STREMEL Silvana. A teoria de Basil Bernstein e algumas de suas contribuições para as pesquisas sobre políticas educacionais e curriculares. Revista Teias, v. 11, n. 22, p. 31-54, maio/agosto 2010.

OLIVEIRA, Amurabi; BOIN, Felipe; BÚRIGIO, Beatriz. Quem tem medo de etnografia? Revista Contemporânea de Educação, v. 13, n. 26, jan/abr 2018.

PEREIRA, Inocêncio Ricardo. Redesenho Curricular no Programa Ensino Médio Inovador: recontextualizações da política. 2017. 145f. Dissertação (Mestrado em Educação). Blumenau, 2017.

PIRES, D.; MORAIS, A. M.; NEVES, I. P. Desenvolvimento científico nos primeiros anos de escolaridade: estudo de características sociológicas específicas da prática pedagógica. Revista Portuguesa de Educação, v. XII, ño. 2, p. 129-132, 2004 
SAMPAIO DE SOUZA, Danilo Fernandes; BAPTISTA Felipe Barreto. O ensino de Língua Portuguesa e Base Nacional Comum Curricular. Saberes, Natal RN, v. 1, n. 17, Dez., 2017, 177-186.

SEVERINO, Antônio Joaquim. Metodologia do trabalho cientifico. 23. ed. rev. e atual. São Paulo: Cortez, 2007.

SOUZA, Janyne Barbosa de. Entre o discurso oficial e o discurso pedagógico: desafios e caminhos construídos, no contexto da rede municipal de ensino de Jequié, no processo de implantação da Lei 10.639/03. 146f. Dissertação (Mestrado em Educação). Universidade Estadual do Sudoeste da Bahia, Vitória da Conquista, 2015.

STEFENON, Daniel Luiz. Desigualdades educacionais e esvąiamento curricular: um estudo a partir do caso de recontextualização dos saberes geográficos na escola. $216 \mathrm{f}$. Tese (Doutorado em Educação). Faculdade de Educação, Universidade de São Paulo, São Paulo, 2017.

UCHOA, Antonio Marcos da Conceição; SENA, Ivânia Paula Freitas de Souza (Orgs.). Diálogos Críticos: BNCC, educação, crise e luta de classes em pauta. Porto Alegre: Fi, 2019.

VITÓRIA DA CONQUISTA. Plano Municipal de Educação. Secretaria Municipal de Educação, Vitória da Conquista, 2019.

. Plano Trimestral de Curso: Língua Portuguesa. Vitória da Conquista, 2019.

Recebido em: 01/04/2020.

Aprovado em: 07/05/2020. 